\title{
Evaluation of Different Analysis Methods for the Encapsulation Efficiency of Amylose Inclusion Compound
}

\author{
Tao Feng, ${ }^{1}$ Fangfang Liu, ${ }^{1}$ Xu Wang, ${ }^{1}$ Haining Zhuang, ${ }^{2}$ Ran Ye, ${ }^{3}$ Zhiwei Rong, ${ }^{4}$ and Yi Liu ${ }^{1}$ \\ ${ }^{1}$ School of Perfume and Aroma Technology, Shanghai Institute of Technology, No. 100 Hai Quan Road, Shanghai 201418, China \\ ${ }^{2}$ Institute of Edible Fungi, Shanghai Academy of Agricultural Sciences, National Engineering Research Center of Edible Fungi, \\ Shanghai 201403, China \\ ${ }^{3}$ Department of Biosystems Engineering \& Soil Science, Tennessee State University, 2506 E.J. Chapman Drive, Knoxville, \\ TN 37996-4531, USA \\ ${ }^{4}$ Shanghai Institute of Daily Chemical Industry, Shanghai 200062, China \\ Correspondence should be addressed to Tao Feng; fengtao@sit.edu.cn and Ran Ye; ran.ye.email@gmail.com
}

Received 1 January 2015; Accepted 4 May 2015

Academic Editor: Alireza Ashori

Copyright (c) 2015 Tao Feng et al. This is an open access article distributed under the Creative Commons Attribution License, which permits unrestricted use, distribution, and reproduction in any medium, provided the original work is properly cited.

\begin{abstract}
Recently amylose has drawn much attention as a potential vehicle for the nanoencapsulation of different flavor molecules, and the encapsulation efficiency of the complex is an important index for the evaluation of its embedding effect. In this study, three different methods for assessing encapsulation efficiency of amylose-flavor complexes were compared. We chose heptanol and menthone as the flavor molecules, as both of them exhibit a typical odor. The complexes were prepared by the melting method, and their structures were characterized by XRD. In addition, the encapsulation efficiency was determined by thermal gravimetric analysis (TGA), potentiometric titration (PT), and headspace solid phase microextraction gas chromatography (HSSPME-GC), respectively. The results showed that PT results were within the reported literature range while HS-SPME-GC seemed to overestimate the results and TGA results were the lowest. What is more, the operations of TGA and PT were relatively simple and the results were reproducible, while the HS-SPME-GC method displayed excellent high sensitivity. Therefore, PT method is the best method for assessing encapsulation efficiency of amylose-flavor complexes.
\end{abstract}

\section{Introduction}

Amylose, the linear fraction of starch, forms crystalline complexes, which is categorized under the general name of $\mathrm{V}$ amylose with a variety of small ligands, including linear alcohols and monoacyl lipids, which consists of a sixfold lefthanded helix repeating at $0.80 \mathrm{~nm}$ (as discussed by Brisson et al. [1], Godet et al. [2, 3], and Le Bail et al. [4]). In addition, other three crystalline types of complexes with branched alcohols have also been reported in the literature. In particular, both $\mathrm{V}_{6}$ and $\mathrm{V}_{8}$ families are identified, respectively, where 6 and 8 represent the number of D-glucosyl unit per turn, respectively. Two inclusion modes have been suggested for $\mathrm{V}_{6}$ types: $\mathrm{V}_{6 \mathrm{I}}, \mathrm{V}_{6 \mathrm{II}}, \mathrm{V}_{6 \mathrm{III}}$, where I, II, and III represent the different spaces between helices in the crystalline stacking. For $\mathrm{V}_{6 \mathrm{I}}$, the small molecules could be entrapped only into the cavity of the helix (as discussed by Godet et al. [2]), and for $\mathrm{V}_{6 \mathrm{II}}$ and $\mathrm{V}_{6 \mathrm{III}}$, the molecules could also be incorporated between helices. Another possibility is that a larger cavity with eight $\mathrm{D}$-glucose units per turn, $\mathrm{V}_{8}$, allows for the inclusion of bulky molecules (as discussed by Le Bail et al. [5], Cardoso et al. [6]).

Compared with $\beta$-cyclodextrin, amylose displays a more flexible folding behavior with different flavor molecules. This may be attributed to the excellent adaptability of amylose, which is precisely distinguished from that of $\alpha$, $\beta$-cyclodextrin $(\alpha, \beta$-CD). Furthermore, some amylosefree fatty acid complexes might form soluble nanoparticles in the aqueous solution. All of these characteristics drive researchers to extensively study the amylose-inclusion complexes using different encapsulation methods (as discussed by Helbert and Chanzy [7], Yang et al. [8], Putaux et al. $[9,10]$, 
and Ades et al. [11]). In particular, many researchers defined different concepts of encapsulation efficiency of amyloseflavor complexes using the identical detection method (as discussed by Wulff et al. [12], Itthisoponkul et al. [13], Cohen et al. [14], and Ades et al. [11]).

For the thermal gravimetric analysis method (TGA), the change of mass varies according to different inclusion complexes. When the secondary factor for the mass loss, such as moisture, was neglected, the difference of loss weight ratio between the control and the inclusion complex could be regarded as the weight ratio of the included compounds. Therefore, the difference of the loss weight ratio was generally employed to calculate the encapsulation efficiency (as discussed by Gunning et al. [15], Ozturk et al. [16]). For the headspace solid phase microextraction gas chromatography method (HS-SPME-GC), the amyloseflavor inclusion compounds were hydrolyzed by $\alpha$-amylase at the ambient temperature, and then the flavor released from the amylose helical-cavity was determined by HS-SPMEGC (as discussed by Arvisenet et al. [17], Wulff et al. [12], and Conde-Petit et al. [18]). In order to use potentiometric titration method (PT), iodine is used as the ligand to form inclusion compounds with amylose. When the spiraled cavity is occupied by guest molecule, the molecular iodine could hardly insert into the cavity. Hence, the difference value of the amylose and amylose-flavor inclusion compounds could be obtained by comparing their potential transition values. Subsequently, the potential transition value is used to calculate the encapsulation efficiency of flavor molecules.

Wulff et al. optimized the formation of helical inclusion compounds of amylose with different typical flavour compounds. Most of the compounds were aldehydes and ketones. Some of them are linear ones, and the others are cyclic ones. It seemed that there were plenty of factors to affect the encapsulation efficiency of the guest molecules such as molecule weight, steric structure, and solubility (as discussed by Wulff et al. [12]). Heptanol exhibited a typical green odor, with fruity aromas of apple and banana, which is generally used in the manufacture of hard candies (as discussed by Mosciano [19]). Menthone is cooling, fresh green and minty with a herbal flavor, which is usually introduced to the production of gums (as discussed by Mosciano et al. [20]). Therefore, heptanol and menthone were selected as flavor compounds in this study.

The main objective of this study was to assess and compare three different analytical methods for the encapsulation efficiency including TGA, HS-SPME-GC, and PT for amylose-heptanol and amylose-menthone complexes. The results achieved from this study can serve as a typical reference for the selection of analytical methods for encapsulation efficiency of amylose inclusion compounds for various purposes.

\section{Materials and Methods}

2.1. Materials. Standard potatoes amylose with the purity at 99\% from Sigma-Aldrich Trading Co., Ltd. (Shanghai, China) was used without further purification; analytical pure grades of anhydrous alcohol, butanol, heptanol, hydrochloric acid, potassium iodide, and potassium iodate were bought from Sinopharm Chemical Reagent Co., Ltd. (Shanghai, China). Menthone was purchased from Heowns Biochemical Reagent Co., Ltd. (Tianjin, China). $\alpha$-Amylase was purchased from Genencor International, Inc. (New York, United States). The activity of the liquid enzyme formulation (protein content was $38 \mathrm{mg} / \mathrm{mL}$ ) was $3000 \mathrm{U} / \mathrm{g}$ of enzyme formulation ( $1 \alpha$ amylase unit, activity unit is the amount of enzyme which breaks down $5.26 \mathrm{~g}$ of starch/h at $37^{\circ} \mathrm{C}$ to glucose at $\mathrm{pH} 5.6$ ) as given in the amylase product data sheet by Novo Nordisk (Shanghai, China).

\subsection{Amylose-Flavor Inclusion Compounds Preparation and} Structural Characterization. As the most common method used for preparation of amylose-flavor inclusion complexes, the melting method followed those used in previous publications with minor modifications (as discussed by CondePetit et al. [18], Jouquand et al. [21]). The total procedure was succinctly described as follows: A $10 \mathrm{~mL}$ dispersion of amylose solution $(0.8 \% \mathrm{w} / \mathrm{v})$ was placed in a pressure vessel (20 $\mathrm{mL}$ pressure bomb, Parr Company) and subsequently was heated up to $150^{\circ} \mathrm{C}$ for $75 \mathrm{~min}$. Then the temperature was naturally cooled to $80^{\circ} \mathrm{C}$ in the vessel and contents were transferred to a flask placed in an $80^{\circ} \mathrm{C}$ water bath for 15 min prior to flavor compound addition. $60 \mathrm{~mL}$ of dispersed amylose was pipetted into a screw-cap test tube, with $60 \mathrm{mg}$ flavor compound. After being vortexed thoroughly, the mixture was stored in a water bath at $80^{\circ} \mathrm{C}$ for $1 \mathrm{~h}$ before cooling to room temperature. Afterwards, amylose-flavor inclusion complexes were maintained at room temperature for $18 \mathrm{~h}$. The wet precipitates were quickly washed by pure anhydrous alcohol and collected after centrifugation at $1700 \mathrm{r} / \mathrm{min}$ for $15 \mathrm{~min}$. Then the precipitates were treated by freeze-dryer (Virtis freeze mobile, US). Dispersed amylose without flavor addition was treated as the control.

X-ray diffraction analyzer (D8 ADVANCE, Bruker, Germany) was used to confirm the amylose-flavor inclusion complex formation. The detail of the detection method is according to Nuessli et al. [22]. Freeze-dried samples were compressed into disks of 1-2 mm thickness and a diameter of $13 \mathrm{~mm}$. The pressed samples were mounted on a sample holder. The measurements were carried out at ambient conditions in the transmission mode on a powder diffractometer (X'Pert Pro, Almelo, Netherlands) using $\mathrm{CuK} \alpha$ radiation $(0.154 \mathrm{~nm})$ with $35 \mathrm{~mA}$ and $40 \mathrm{kV}$. A divergence slit of $2 \mathrm{~mm}$ and a receiving slit of $1^{\circ}$ were selected. Nickel filter was used in this detection. The relative intensity was recorded in a scattering angle range $(2 \theta)$ of $5-30^{\circ}$ with a scintillation counter at a scanning speed of $0.04^{\circ} / \mathrm{min}$. The diffractograms were reduced by the Fourier filtered diffractogram.

\subsection{Determination Methods}

2.3.1. Thermal Gravimetric Analysis (TGA). Thermal gravimetric analysis (TGA) was carried out with a TGA Q2000 (TA Instruments, USA). All analysis was performed with a $3 \sim 5 \mathrm{mg}$ sample in an open aluminum pans under nitrogen 
atmosphere, and the gas flow rate was $40 \mathrm{~mL} / \mathrm{min}$. Then the sample was heated at a constant rate of $10^{\circ} \mathrm{C} / \mathrm{min}$ during the analysis and the final temperature was up to $400^{\circ} \mathrm{C}$. Pure amylose was used as the blank sample. Encapsulation efficiency was calculated as

Encapsulation efficiency

$$
\begin{aligned}
= & \frac{\text { Mass loss }}{\text { amylose inclusion compounds }}-\text { Mass } \operatorname{loss}_{\text {Standard amylose }} \\
& \text { Mass }_{\text {amylose inclusion compounds }} \\
& \times 100 \% \text {. }
\end{aligned}
$$

2.3.2. Potentiometric Titration Method (PT). Potentiometric titration method was carried out with an autotitrator (Mettler Toledo DL50) equipped with a DM140 platinum electrode, DV1010 burette, and LabX light titration software (version 2). Recognition of the equivalence point (EQP) was set by adjusting the threshold to appropriate values. Termination of the titration occurred after one equivalence point was reached, or the maximum volume of the burette $(10.0 \mathrm{~mL})$ was dispensed. The titer of potassium iodate solution was found by independent experiments and had a value of $0.098 \pm$ $0.003 \mathrm{~mol} / \mathrm{L}, p<0.05$ (significant difference). The software reported the volume of titrant at EQP; iodine affinity (IA, \%), flavor affinity (FA, \%) could be calculated by the equation.

The iodine was produced by the reaction of the potassium iodide with titrant $\mathrm{KIO}_{3}$ and hydrochloric acid, which binds to amylose as shown in the following formula:

$$
\mathrm{IO}_{3}{ }^{-}+6 \mathrm{H}^{+}+5 \mathrm{I}^{-} \longrightarrow 3 \mathrm{I}_{2}+3 \mathrm{H}_{2} \mathrm{O} \text {. }
$$

The iodine affinity (IA, \%) was calculated from the volume (VEQ, mL) of titrant at EQP using

$$
\mathrm{IA}(\%)=\frac{\mathrm{VEQ} \times c \times z \times M \times 100}{m} \times 100 \% \text {, }
$$

where $c=0.01 \mathrm{~mol} / \mathrm{L}$ which is the nominal concentration of the titrant and $z=3$, which is the stoichiometric factor of the $\mathrm{I}_{2}$ production reaction. $M=254 \mathrm{~g} / \mathrm{mol}$, which is the molecule weight of $\mathrm{I}_{2}$, and $m$ is the dry mass of the inclusion sample (mg).

Flavor content was calculated from the ratio of iodine affinity of the inclusion compound to the iodine affinity of amylose standard sample as the above equation (as discussed by Bhatnagar and Hanna [23]).

In solution, iodine can enter into the spiraled cavity of amylose and form complex compounds, but iodine cannot form complex compound with amylose-flavor molecule inclusion compounds. With the potassium iodate trickling, the excessive iodine formed in the solution after all of the amylose had been included with iodine and the electrode potential transition of $\mathrm{I}^{-} / \mathrm{I}_{2}$ ion pairs indicated the titration end point.

The standard curve and the titration curve can be drawn, with the consumed volume of potassium iodate standard solution for the $x$-axis and the potential readings for the $y$ axis. The content of flavor molecules was calculated from the ratio of iodine affinity of the inclusion compounds and the iodine affinity of pure amylose. Curves a e were the potential titration curves for inclusion compound and amylose standard sample in Figures 1s and 2s (in Supplementary Material available online at http://dx.doi.org/10.1155/2015/645916). The encapsulation efficiency of each compound was the consumed volume difference and calculated as the following equation:

$$
\begin{aligned}
& \text { Encapsulation Efficiency }(\%) \\
& \qquad=\frac{\mathrm{IA}_{\text {amylose }}-\mathrm{IA}_{\text {compound }}}{\text { Mass }_{\text {compound }}} \times 100 \% .
\end{aligned}
$$

2.3.3. Head-Space Solid Phase Microextraction Gas Chromatography (HS-SPME-GC). HS-SPME-GC analysis was performed on an Agilent 6890 Gas Chromatograph (HP, USA). The samples in headspace glass vessels were placed at $25^{\circ} \mathrm{C}$ for 1 hour before the analysis. Ten milliliters of the amylose complex solution was in each bottle which contains $3 \mathrm{~g}$ of inclusion compounds $\left(C_{0}=0.3 \mathrm{~g} / \mathrm{mL}\right)$ and $1 \mathrm{mg}$ of salivary amylase. A SPME (Supelco Co., Bellefonte, PA) fiber coated with polydimethylsiloxane (PDMS, $1 \mathrm{~cm}$ long, $100 \mu \mathrm{m}$ thickness) was used to collect and concentrate flavors by virtue of its sorption characteristics (as discussed by Arthur and Pawliszyn [24]). The SPME device consisted of a retractable fiber enclosed in a sheath. During sampling, after entering the sample container, the fiber was extended, exposing the sorption surface. The fiber was then retracted prior to removal from the sample container. Each sample was adsorbed for $30 \mathrm{~min}$, and the volatiles were desorbed from the fiber for $90 \mathrm{~s}$ at $250^{\circ} \mathrm{C}$ into the glass-lined, splitless injector port of a GC (HP-6890, Hewlett Packard Co.). The fiber was preconditioned at $250^{\circ} \mathrm{C}$ for $1 \sim 2 \mathrm{~h}$. All SPME samplings were carried out at $25^{\circ} \mathrm{C}$ in triplicate unless otherwise noted. The obtained extracts were analyzed with an HP-5 column (5\% phenyl 95\% methyl siloxane, $30.0 \mathrm{~m} \times$ $250.0 \mu \mathrm{m} \times 0.25 \mu \mathrm{m})$. Three analyses were conducted for each product and after that the average value was calculated. The temperature program was as follows: The chromatographic conditions were held at $75^{\circ} \mathrm{C}$ for $5 \mathrm{~min}$, then increased at a $5^{\circ} \mathrm{C} / \mathrm{min}$ rate to $100^{\circ} \mathrm{C}$, and then ramped at $10^{\circ} \mathrm{C} / \mathrm{min}$ to $200^{\circ} \mathrm{C}$. For menthone detection, $200^{\circ} \mathrm{C}$ is maintained for $5 \mathrm{~min}$; for heptanol detection, $180^{\circ} \mathrm{C}$ is kept for $25 \mathrm{~min}$. The flow rate of nitrogen carrier gas, hydrogen, air, and nitrogen makeup gas was $2.4 \mathrm{~mL} / \mathrm{min}, 40 \mathrm{~mL} / \mathrm{min}, 400 \mathrm{~mL} / \mathrm{min}$, and $45 \mathrm{~mL} / \mathrm{min}$, respectively. Injection temperature was $250^{\circ} \mathrm{C}$ and detection temperature was $250^{\circ} \mathrm{C}$. Peaks were identified using HPGC ChemStation software (Agilent Co. Ltd, USA). Standards for the aroma were used in order to identify the peaks. We use this equation to convert the peak area into concentration, $C_{\text {sample }}: C_{\text {standard }}=A_{\text {sample }}: A_{\text {standard }}$. Response factors were measured through the software and employed to convert peak areas into concentrations $\left(C_{t}\right)$ of flavor compounds.

2.4. Experimental Design and Statistical Analysis. The experiments were designed based on a fractional factorial design, and the results represent the means of three replicates. The statistical analysis was performed using SPSS version 18.0, 


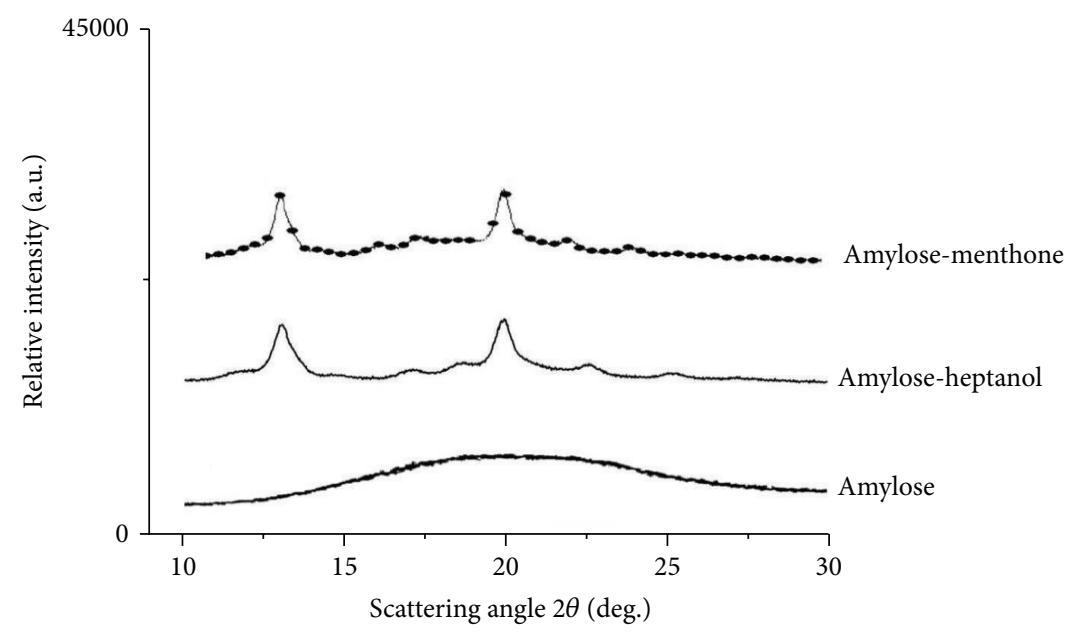

FIGURE 1: XRD diffractograms of amylose (thick solid line), amylose-menthone (-๑-), and amylose-heptanol (thin solid line) complexes.

and all graphs were created using Origin Pro 8 (Origin Lab Corporation, Northampton, USA).

\section{Results and Discussion}

3.1. Amylose-Flavor Inclusion Complex Preparation and Structural Confirmation. Well-dispersed potato amylose without any flavor substance served as a reference, and the corresponding X-ray diffraction patterns are shown in Figure 1. Xray analysis of amylose yielded an amorphous halo, indicating the absence of the preexisting complex and the retrogradation effect. X-ray analysis of both amylose-menthone and amylose-heptanol complexes yielded a typical $\mathrm{V}_{6 \mathrm{I}}$ amylose pattern with scattering angles $(2 \theta)$ of $13^{\circ}$ and $20^{\circ}$, suggesting the presence of crystalline structures of the amylosementhone and amylose-heptanol complexes. The diffraction diagram is characteristic for a single amylose helix with $6 \mathrm{D}$ glucosyl units per turn. It was most likely that the ligand was included in the helix cavity.

3.2. Thermal Gravimetric Method. The encapsulation efficiency of the prepared inclusion compound and the actual mass of the encapsulated flavor molecules remained unknown. Therefore, according to the results of the TGA, it was demonstrated that the encapsulated amount of flavor molecules ranged from $1 \mathrm{mg}$ to $2.5 \mathrm{mg}$ after the addition of $5 \mathrm{mg}$ flavor molecules into amylose. However, little published information is available about encapsulation efficiency determination of amylose inclusion complex with TGA method. Table 1 listed thermal gravimetric analysis of amylose-heptanol and amylose-menthone molecules inclusion complexes, which partially agreed with those determined by potentiometric titration and $\alpha$-amylase/GC methods.

Figure 2 illustrated that inclusion compounds were analyzed by TGA method, revealing the similar encapsulation efficiency for two amylose-flavor complexes although heptanol and menthone have different inherent physicochemical properties. The mass loss at the first decomposition stage occurred at $60 \sim 70^{\circ} \mathrm{C}$. It was well-recognized that both parts of water loss and a small amount of flavor compounds, which did not form a stable complex with amylose, contributed to the loss. However, this partial loss would not interfere with the evaluation of the encapsulation efficiency (as discussed by Choi et al. [25]). They compared the eugenol encapsulation efficiency of $\beta$-CD, 2-HP- $\beta$-CD, and polycaprolactone (PCL) by TGA, respectively. The weight loss of both $\beta-\mathrm{CD}$ and $2-$ HP- $\beta$-CD was evident. It could be attributed to evaporation of water. However, the weight loss of free-eugenol with PCL was unremarkable. Furthermore, the encapsulation efficiency of $\beta$-CD was more effective than that of $2-\mathrm{HP}-\beta-\mathrm{CD}$ (as discussed by Choi et al. [25]).

The mass loss at the second decomposition stage was in the range from 300 to $370^{\circ} \mathrm{C}$. This part of the mass loss was mainly due to the dissociation of amylose at high temperature, thereby leading to breakdown of the structure and the quick volatilization of the contained flavor molecules. The result also showed that the mass loss at this stage was larger than that of control. The second part of mass loss of the flavor molecules was considered as the amount of the encapsulated flavor, and the ratio of the mass loss of the flavor molecules divided by that of the inclusion compound was defined as the encapsulation efficiency of each flavor inclusion.

As depicted in Figure 2 and Table 1, the mass loss of the complex containing heptanol was slightly higher than that of menthone, and both were higher than the control. It was indicated that the encapsulation efficiency of heptanol was higher than that of menthone under the identical experimental condition. It may be due to the linear molecular structure and the relatively higher solubility of heptanol, corresponding to the higher dispersibility of heptanol in gelatinized amylose solution. However, menthone with more steric hindrance structure and relative lower solubility might cause the lower encapsulation efficiency. 
TABLE 1: Thermal gravimetric analysis of amylose-heptanol and amylose-menthone molecules inclusion complexes.

\begin{tabular}{lcccc}
\hline Test results & \multicolumn{2}{c}{ Sample label } \\
& Amylose-0.1 mol flavor & Amylose-0.2 mol flavor & Amylose-0.3 mol flavor & Amylose-0.4 mol flavor \\
\hline Weight loss rate\% & & & & \\
$\quad$ & & & \\
$\quad$ Heptanol & $1.49 \pm 0.01^{\mathrm{Aa}}$ & $1.68 \pm 0.01^{\mathrm{Bb}}$ & $1.84 \pm 0.02^{\mathrm{C}}$ & $1.75 \pm 0.01^{\mathrm{B}}$ \\
$\quad$ Menthone & $1.42 \pm 0.01^{\mathrm{A}}$ & $1.61 \pm 0.01^{\mathrm{B}}$ & & $1.72 \pm 0.01^{\mathrm{B}}$ \\
Encapsulation efficiency\% & & & \\
$\quad$ Heptanol & $35.45 \pm 0.02^{\mathrm{A}}$ & $40.25 \pm 0.01^{\mathrm{B}}$ & $44.85 \pm 0.02^{\mathrm{C}}$ & $42.25 \pm 0.02^{\mathrm{B}}$ \\
$\quad$ Menthone & $33.82 \pm 0.02^{\mathrm{A}}$ & $38.24 \pm 0.01^{\mathrm{B}}$ & $44.47 \pm 0.02^{\mathrm{C}}$ & $41.39 \pm 0.02^{\mathrm{B}}$ \\
\hline
\end{tabular}

${ }^{a}$ Values are mean of triplicate determination \pm standard deviation.

${ }^{\mathrm{b}}$ Difference is significant at the same row with different capital letters, $p<0.05$.

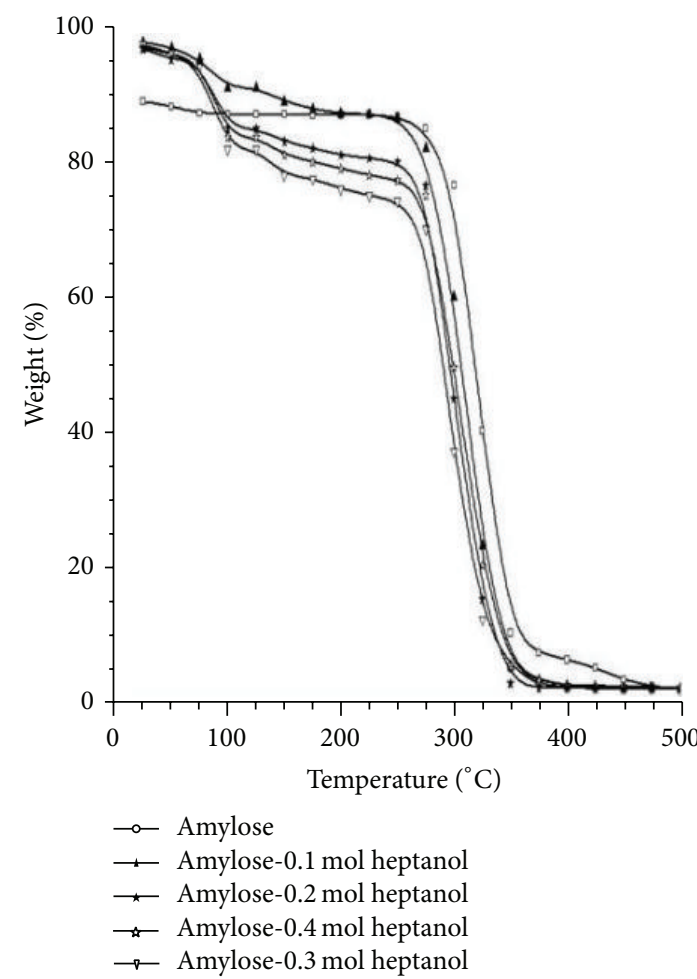

(a)

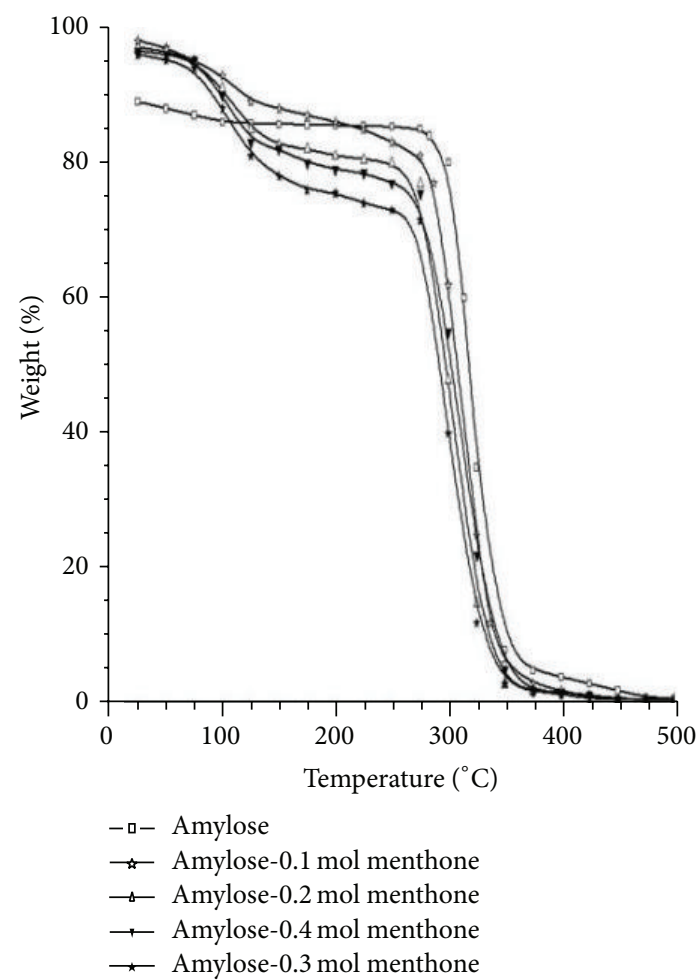

(b)

FIGURE 2: TGA curves of amylose-heptanol (a), amylose-menthone (b) inclusion complexes.

3.3. Potentiometric Titration. Potentiometric titration analysis of amylose-flavor molecules inclusion complexes was listed in Table 2.

A typical titration profile of amylose with potassium iodate is shown in Figures 1s and 2s. The sharp peak of the 1st derivative of the potential indicated the equivalence point of the reactions (Figures $3 \mathrm{~s}$ and $4 \mathrm{~s}$ ). Of note, the potentiometric titration method employed in this study was different from the potentiometric titration method (as discussed by Duan et al. [26]), which determined the amount of bound iodine by extrapolation of ascorbic acid. They reported that potentiometric titration results for potato starches were comparable to those reported in literature while the colorimetric method seemed to overestimate amylose content. Another advantage of potentiometric titration is that it does not require the starch solution to be clear and colorless. Otherwise, it has to compromise the colorimetric method if the color and precipitates exist in the sample solutions. The titer of potassium iodate solution was found by independent experiments and had a value of $0.098 \pm 0.003 \mathrm{~mol} / \mathrm{L}$. Linearity of the method was tested using amylose (1 20 mg) and inclusion compound (3 $50 \mathrm{mg}$ ). The method exhibited excellent linearity as shown in Figure 3, with $R^{2}$ values of $0.9975,0.9988$, and 0.9961 for amylose, amylose-heptanol, and amylose-menthone inclusion compound, respectively.

Heinemann et al. [27] used amperometric iodine titration to determine the extent of amylose complexation. They calculated the iodine binding capacity of the uncomplexed starch $\left(\mathrm{IBC}_{\mathrm{ref}}\right)$ and complexed starch (IBC), respectively. The degree of complexation (DC) was calculated by 
TABLE 2: Potentiometric titration analysis of amylose-heptanol and amylose-menthone molecules inclusion complexes.

\begin{tabular}{lcc}
\hline \multirow{2}{*}{ Sample description } & \multicolumn{2}{c}{ Test result } \\
& $\begin{array}{c}\text { Equivalence } \\
\text { volume (EVQ, mL) }\end{array}$ & $\begin{array}{c}\text { Encapsulation } \\
\text { efficiency (\%) }\end{array}$ \\
\hline Amylose-0.1 mol heptanol & $3.58 \pm 0.01^{\mathrm{Ba}}$ & $41.23 \pm 0.02^{\mathrm{B}}$ \\
Amylose-0.2 mol heptanol & $4.24 \pm 0.01^{\mathrm{A}}$ & $45.07 \pm 0.02^{\mathrm{AB}}$ \\
Amylose-0.3 mol heptanol & $4.89 \pm 0.02^{\mathrm{A}}$ & $48.86 \pm 0.03^{\mathrm{A}}$ \\
Amylose-0.4 mol heptanol & $4.76 \pm 0.01^{\mathrm{A}}$ & $48.09 \pm 0.03^{\mathrm{A}}$ \\
Amylose-0.1 mol menthone & $3.35 \pm 0.01^{\mathrm{B}}$ & $40.97 \pm 0.02^{\mathrm{B}}$ \\
Amylose-0.2 mol menthone & $4.34 \pm 0.02^{\mathrm{B}}$ & $44.86 \pm 0.01^{\mathrm{AB}}$ \\
Amylose-0.3 mol menthone & $4.82 \pm 0.02^{\mathrm{A}}$ & $48.36 \pm 0.02^{\mathrm{A}}$ \\
Amylose-0.4 mol menthone & $4.68 \pm 0.01^{\mathrm{A}}$ & $47.46 \pm 0.02^{\mathrm{A}}$ \\
\hline
\end{tabular}

${ }^{a}$ Difference is significant at the same column with different capital letters, $p<0.05$.

${ }^{\mathrm{b}}$ The peak area value is average of three parallel samples.

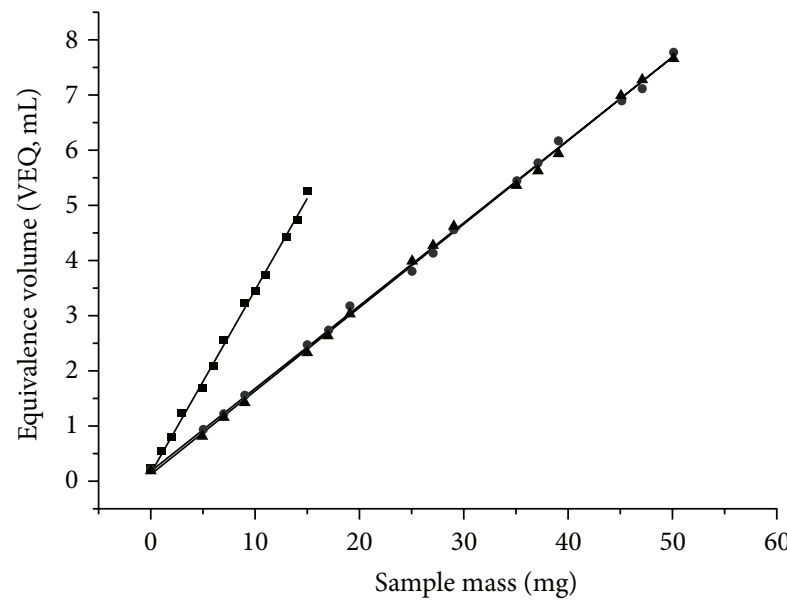

-- Linear fit of amylose

-•- Linear fit of amy-hept

-\$- Linear fit of amy-men

\begin{tabular}{lccc}
\hline Equation & \multicolumn{3}{c}{$y+b * x$} \\
\hline Adj. $R^{2}$ & 0.99754 & 0.9988 & 0.99614 \\
& & Value & Standard error \\
Amylose & Intercept & 0.17218 & 0.04169 \\
Amylose & Slope & 0.32918 & 0.00472 \\
Amy-hept & Intercept & 0.19823 & 0.03971 \\
Amy-hept & Slope & 0.1495 & 0.00134 \\
Amy-men & Intercept & 0.10766 & 0.03395 \\
Amy-men & Slope & 0.1514 & 0.00114 \\
\hline
\end{tabular}

Figure 3: The curves of the potentiometric titration and sample mass.

$\left(\mathrm{IBC}_{\mathrm{ref}}-\mathrm{IBC}\right) / \mathrm{IBC}_{\mathrm{ref}} * 100 \%$. The $\mathrm{DC}$ of $10 \mathrm{mmol} \delta$-Dodecalactone/mol glucose was obtained at $2 \mathrm{~g}$ dry starch/100 $\mathrm{g}$ aqueous solution about 55\%. In present study, encapsulation efficiency of $0.1 \sim 0.4 \mathrm{~mol}$ flavor compound per mol glucose at $8 \mathrm{~mL}$ amylose aqueous solution $(0.8 \%$, w/v) had been determined by this method. In Table 2 , it was demonstrated that the highest encapsulation efficiency was reached at both

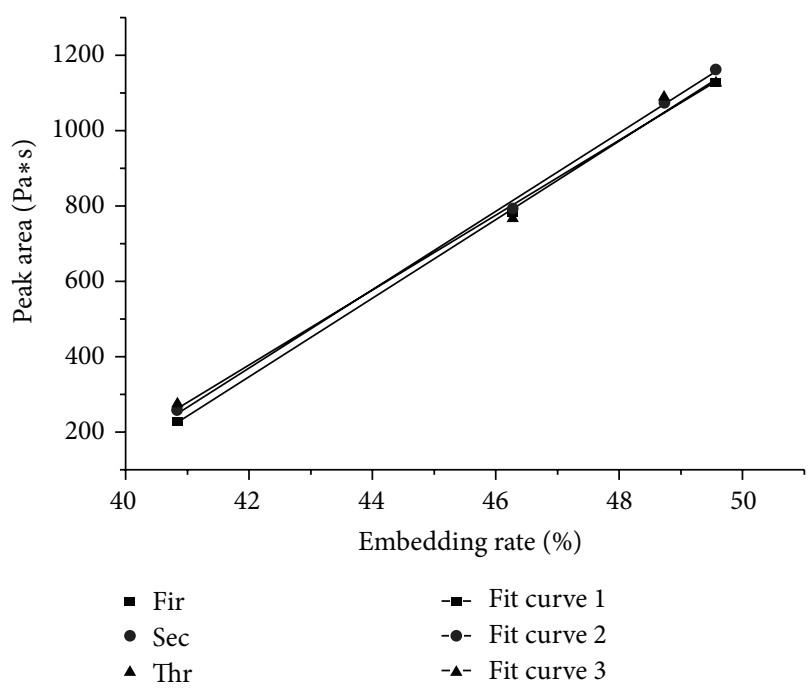

\begin{tabular}{lccc}
\hline Equation & \multicolumn{3}{c}{$y=a+b * x$} \\
\hline Adj. $R^{2}$ & 0.9975 & 0.99872 & 0.9878 \\
& & Value & Standard error \\
Curve 1 & Intercept & -4058.352 & 138.47161 \\
Curve 1 & Slope & 104.8560 & 2.97967 \\
Curve 2 & Intercept & -4003.369 & 99.89463 \\
Curve 2 & Slope & 104.1032 & 2.14956 \\
Curve 3 & Intercept & -3840.601 & 298.66697 \\
Curve 3 & Slope & 100.3797 & 6.42679 \\
\hline
\end{tabular}

FIGURE 4: The curves of the headspace solid phase microextraction gas chromatography method.

$0.3 \mathrm{~mol}$ heptanol and menthone/mol glucose with $48.86 \pm$ $0.03 \%$ and $48.36 \pm 0.02$, respectively, suggesting that $0.3 \mathrm{~mol}$ flavor compound per mol glucose might be an optimal concentration for amylose inclusion. The difference between present studies and Heinemann et al. [27] might be caused by different guest molecules and different encapsulation conditions.

The determination limitation of the method was detected to be $\sim 2 \mathrm{mg}$ of amylose (equivalent to $6 \mathrm{mg}$ of inclusion compound). When the amount of flavor was lower than the determination limit, $1 \mathrm{mg}$ relative standard deviation (RSD) was increased. It was probably due to the detection limit of the electrode. On the other hand, it should be noted that RSD was also increased as the mass of the sample was increased from 40 to $50 \mathrm{mg}$. This could be caused by the higher volume of titrant required for a larger amount of the inclusion compound.

3.4. Headspace Solid Phase Microextraction Gas Chromatography Method. The curves of headspace solid phase microextraction gas chromatography analysis were shown in Figure 4. The encapsulation efficiency was calculated as the following: Firstly, the concentration of guest molecule before complexation in the headspace of vessel was determined as $C_{0}$. Secondly, the concentration of guest molecule after complexation in the headspace of vessel was determined as $C_{1}$. Finally, the encapsulation efficiency was calculated as $\left(C_{0}-C_{1}\right) / C_{1} *$ 
TABLE 3: Headspace solid phase microextraction gas chromatography analysis of amylose-heptanol and amylose-menthone molecules inclusion complexes.

\begin{tabular}{|c|c|c|c|}
\hline \multirow[b]{2}{*}{ Sample description } & \multicolumn{3}{|c|}{ Test result } \\
\hline & $\begin{array}{l}\text { Peak area } \\
(\mathrm{Pa} * \mathrm{~s})\end{array}$ & RSD & $\begin{array}{l}\text { Encapsulation } \\
\text { efficiency (\%) }\end{array}$ \\
\hline $\begin{array}{l}\text { Amylose- } 0.1 \mathrm{~mol} \\
\text { heptanol }\end{array}$ & $246.35262^{\mathrm{Bb}}$ & $3.77 \%$ & $40.84 \pm 0.01^{\mathrm{A}}$ \\
\hline $\begin{array}{l}\text { Amylose- } 0.2 \mathrm{~mol} \\
\text { heptanol }\end{array}$ & $781.26936^{\mathrm{A}}$ & $2.58 \%$ & $46.27 \pm 0.01^{\mathrm{B}}$ \\
\hline $\begin{array}{l}\text { Amylose- } 0.3 \mathrm{~mol} \\
\text { heptanol }\end{array}$ & $1105.49261^{B}$ & $1.64 \%$ & $49.56 \pm 0.01^{\mathrm{B}}$ \\
\hline $\begin{array}{l}\text { Amylose- } 0.4 \mathrm{~mol} \\
\text { heptanol }\end{array}$ & $1022.73399^{\mathrm{A}}$ & $1.87 \%$ & $48.72 \pm 0.01^{\mathrm{B}}$ \\
\hline $\begin{array}{l}\text { Amylose- } 0.1 \mathrm{~mol} \\
\text { menthone }\end{array}$ & $244.89567^{\mathrm{B}}$ & $3.65 \%$ & $40.02 \pm 0.01^{\mathrm{A}}$ \\
\hline $\begin{array}{l}\text { Amylose- } 0.2 \mathrm{~mol} \\
\text { menthone }\end{array}$ & $779.53634^{\text {B }}$ & $2.52 \%$ & $45.74 \pm 0.01^{\mathrm{AB}}$ \\
\hline $\begin{array}{l}\text { Amylose- } 0.3 \mathrm{~mol} \\
\text { menthone }\end{array}$ & $1103.78354^{\mathrm{B}}$ & $1.60 \%$ & $49.26 \pm 0.01^{\mathrm{B}}$ \\
\hline $\begin{array}{l}\text { Amylose- } 0.4 \mathrm{~mol} \\
\text { menthone }\end{array}$ & $1020.45734^{\mathrm{A}}$ & $1.84 \%$ & $47.88 \pm 0.01^{\mathrm{B}}$ \\
\hline
\end{tabular}

$100 \%$. It was demonstrated that the encapsulation efficiencies of the two sets of inclusion compounds were comparable. In Table 3, it was demonstrated that the encapsulation efficiency of heptanol was slightly higher than that of menthone, which was quite close to the results determined by potentiometric titration.

Most published studies reported the GC method by using alkali hydrolysis and solvent extraction (as discussed by Mongenot et al. [28], Yilmaz et al. [29], Jeon et al. [30], and Tapanapunnitikul et al. [31]). Nevertheless, the new factor has to be considered since the solvent evaporation leads to the loss of the sample and incomplete extraction. In present study, we used $\alpha$-amylase and HS-SPME-GC to determine the volatile guest molecules encapsulated by amylose. The advantages of this method contained the absence of alkali hydrolysis and the employment of solvent extraction. In contrast, the shortcoming is that guest molecules have to be volatile.

The HS-SPME-GC method requires the flavor molecule for the construction of a standard curve, in which the results are highly associated with the concentration of the flavor molecule. The iodine affinity of the standard amylose estimated by using potentiometric titration had encapsulation efficiency value as low as $40 \% \sim 45 \%$, slightly higher than that of TGA (40\%). This could explain why the HS-SPMEGC method somehow overestimated the flavor molecule content of these samples. On the other hand, differences in the molecular characteristics of heptanol and menthone may be another reason resulting in the variation. Furthermore, comparison of $\gamma$-decalactone and $\delta$-decalactone also showed the similar results as in other amylose inclusion compound samples (as discussed by Heinemann et al. [32]).
Moreover, amylase used in this section is an enzyme that hydrolyzes amylose into small fragments. This enzyme has the three-dimensional structure, which may lead to a certain degree of adsorption of flavor molecules. The measured peak areas of each inclusion compound had small difference with a standard deviation of less than $3 \%$.

Three different methods (the thermal gravimetric method, the potentiometric titration method, and the headspace solid phase microextraction gas chromatography method) were used to evaluate the encapsulation efficiency of amylose-flavor complex. Compared to the results of the three methods, PT results were within the reported literature range (as discussed by Duan et al. [26]), while HS-SPME-GC seemed to overestimate the results and TGA results were the lowest. What is more, TGA is simple and straightforward, and the results are reproducible, but there is little literature about encapsulation efficiency determination of amylose inclusion complex. PT is accurate and reproducible, and the operation was relatively simple, but the calculation was slightly complicated. HS-SPME-GC exhibited high sensitivity, but it required costly instrumentation with carefully protective maintenance and complex operation procedure.

\section{Conclusions}

Compared to the results of the three analytical methods, PT results were the most accurate while TGA results were the lowest and HS-SPME-GC seemed to overestimate the results. Therefore, PT method is the best method for assessing encapsulation efficiency of amylose-flavor complexes.

\section{Conflict of Interests}

The authors declare that there is no conflict of interests regarding the publication of this paper.

\section{Acknowledgment}

This study is financially supported by National Natural Science Foundation of China for Young Scholars (31000794).

\section{References}

[1] J. Brisson, H. Chanzy, and W. T. Winter, "The crystal and molecular structure of $\mathrm{V}_{H}$ amylose by electron diffraction analysis," International Journal of Biological Macromolecules, vol. 13, no. 1, pp. 31-39, 1991.

[2] M. C. Godet, H. Bizot, and A. Buléon, "Crystallization of amylose-fatty acid complexes prepared with different amylose chain lengths," Carbohydrate Polymers, vol. 27, no. 1, pp. 47-52, 1995.

[3] M. C. Godet, A. Buléon, V. Tran, and P. Colonna, "Structural features of fatty acid-amylose complexes," Carbohydrate Polymers, vol. 21, no. 2-3, pp. 91-95, 1993.

[4] P. Le Bail, H. Bizot, B. Pontoire, and A. Buléon, "Polymorphic transitions of amylose-ethanol crystalline complexes induced by moisture exchanges," Starch-Stärke, vol. 47, no. 6, pp. 229232, 1995. 
[5] P. Le Bail, C. Rondeau, and A. Buléon, "Structural investigation of amylose complexes with small ligands: helical conformation, crystalline structure and thermostability," International Journal of Biological Macromolecules, vol. 35, no. 1-2, pp. 1-7, 2005.

[6] M. B. Cardoso, J.-L. Putaux, Y. Nishiyama et al., "Single crystals of V-amylose complexed with $\alpha$-naphthol," Biomacromolecules, vol. 8, no. 4, pp. 1319-1326, 2007.

[7] W. Helbert and H. Chanzy, "Single crystals of V amylose complexed with n-butanol or n-pentanol: structural features and properties," International Journal of Biological Macromolecules, vol. 16, no. 4, pp. 207-213, 1994.

[8] Y. Yang, Z. B. Gu, H. Xu, F. Li, and G. Zhang, "Interaction between amylose and $\beta$-cyclodextrin investigated by complexing with conjugated linoleic acid," Journal of Agricultural and Food Chemistry, vol. 58, no. 9, pp. 5620-5624, 2010.

[9] J.-L. Putaux, Y. Nishiyama, K. Mazeau, M. Morin, M. B. Cardoso, and H. Chanzy, "Helical conformation in crystalline inclusion complexes of $\mathrm{V}$-amylose: a historical perspective," Macromolecular Symposia, vol. 303, no. 1, pp. 1-9, 2011.

[10] J.-L. Putaux, N. Montesanti, G. Véronse, and A. Buléon, "Morphology and structure of A-amylose single crystals," Polymer, vol. 52, no. 10, pp. 2198-2205, 2011.

[11] H. Ades, E. Kesselman, Y. Ungar, and E. Shimoni, "Complexation with starch for encapsulation and controlled release of menthone and menthol," LWT-Food Science and Technology, vol. 45, no. 2, pp. 277-288, 2012.

[12] G. Wulff, G. Avgenaki, and M. S. P. Guzmann, "Molecular encapsulation of flavours as helical inclusion complexes of amylose," Journal of Cereal Science, vol. 41, no. 3, pp. 239-249, 2005.

[13] T. Itthisoponkul, J. R. Mitchell, A. J. Taylor, and I. A. Farhat, "Inclusion complexes of tapioca starch with flavour compounds," Carbohydrate Polymers, vol. 69, no. 1, pp. 106-115, 2007.

[14] R. Cohen, Y. Orlova, M. Kovalev, Y. Ungar, and E. Shimoni, "Structural and functional properties of amylose complexes with genistein," Journal of Agricultural and Food Chemistry, vol. 56, no. 11, pp. 4212-4218, 2008.

[15] Y. M. Gunning, P. A. Gunning, E. K. Kemsley et al., "Factors affecting the release of flavor encapsulated in carbohydrate matrixes," Journal of Agricultural and Food Chemistry, vol. 47, no. 12, pp. 5198-5205, 1999.

[16] S. Ozturk, H. Koksel, K. Kahraman, and P. K. W. Ng, "Effect of debranching and heat treatments on formation and functional properties of resistant starch from high-amylose corn starches," European Food Research and Technology, vol. 229, no. 1, pp. 115125, 2009.

[17] G. Arvisenet, P. L. Bail, A. Voilley, and N. Cayot, "Influence of physicochemical interactions between amylose and aroma compounds on the retention of aroma in food-like matrices," Journal of Agricultural and Food Chemistry, vol. 50, no. 24, pp. 7088-7093, 2002.

[18] B. Conde-Petit, F. Escher, and J. Nuessli, "Structural features of starch-flavor complexation in food model systems," Trends in Food Science and Technology, vol. 17, no. 5, pp. 227-235, 2006.

[19] G. Mosciano, "The creative flavorist: Oxford chemicals," Perfumer and Flavorist, vol. 26, no. 5, pp. 68-71, 2001.

[20] G. Mosciano, M. Fasano, J. Cassidy et al., "Organoleptic characteristics of flavor materials," Perfumer \& Flavorist, vol. 18, no. 6, pp. 33-35, 1993.

[21] C. Jouquand, V. Ducruet, and P. le Bail, "Formation of amylose complexes with C6-aroma compounds in starch dispersions and its impact on retention," Food Chemistry, vol. 96, no. 3, pp. 461-470, 2006.
[22] J. Nuessli, B. Sigg, B. Conde-Petit, and F. Escher, "Characterization of amylose-flavour complexes by DSC and X-ray diffraction," Food Hydrocolloids, vol. 11, no. 1, pp. 27-34, 1997.

[23] S. Bhatnagar and M. A. Hanna, "Amylose-lipid complex formation during single-screw extrusion of various corn starches," Cereal Chemistry, vol. 71, no. 6, pp. 582-587, 1994.

[24] C. L. Arthur and J. Pawliszyn, "Solid phase microextraction with thermal desorption using fused silica optical fibers," Analytical Chemistry, vol. 62, no. 19, pp. 2145-2148, 1990.

[25] M. J. Choi, A. Soottitantawat, O. Nuchuchua, S.-G. Min, and U. Ruktanonchai, "Physical and light oxidative properties of eugenol encapsulated by molecular inclusion and emulsiondiffusion method," Food Research International, vol. 42, no. 1, pp. 148-156, 2009.

[26] D. X. Duan, E. Donner, Q. Liu, D. C. Smith, and F. Ravenelle, "Potentiometric titration for determination of amylose content of starch-a comparison with colorimetric method," Food Chemistry, vol. 130, no. 4, pp. 1142-1145, 2012.

[27] C. Heinemann, M. Zinsli, A. Renggli, F. Escher, and B. CondePetit, "Influence of amylose-flavor complexation on build-up and breakdown of starch structures in aqueous food model systems," LWT-Food Science and Technology, vol. 38, no. 8, pp. 885-894, 2005.

[28] N. Mongenot, S. Charrier, and P. Chalier, "Effect of ultrasound emulsification on cheese aroma encapsulation by carbohydrates," Journal of Agricultural and Food Chemistry, vol. 48, no. 3, pp. 861-867, 2000.

[29] G. Yilmaz, G. Öngen, R. O. J. Jongboom, H. Feil, C. van Dijk, and W. E. Hennink, "Modulated release of a volatile compound from starch matrixes via enzymatically controlled degradation," Biomacromolecules, vol. 3, no. 2, pp. 305-311, 2002.

[30] Y.-J. Jeon, T. Vasanthan, F. Temelli, and B.-K. Song, “The suitability of barley and corn starches in their native and chemically modified forms for volatile meat flavor encapsulation," Food Research International, vol. 36, no. 4, pp. 349-355, 2003.

[31] O. Tapanapunnitikul, S. Chaiseri, D. G. Peterson, and D. B. Thompson, "Water solubility of flavor compounds influences formation of flavor inclusion complexes from dispersed highamylose maize starch," Journal of Agricultural and Food Chemistry, vol. 56, no. 1, pp. 220-226, 2008.

[32] C. Heinemann, B. Conde-Petit, J. Nuessli, and F. Escher, "Evidence of starch inclusion complexation with lactones," Journal of Agricultural and Food Chemistry, vol. 49, no. 3, pp. 1370-1376, 2001. 

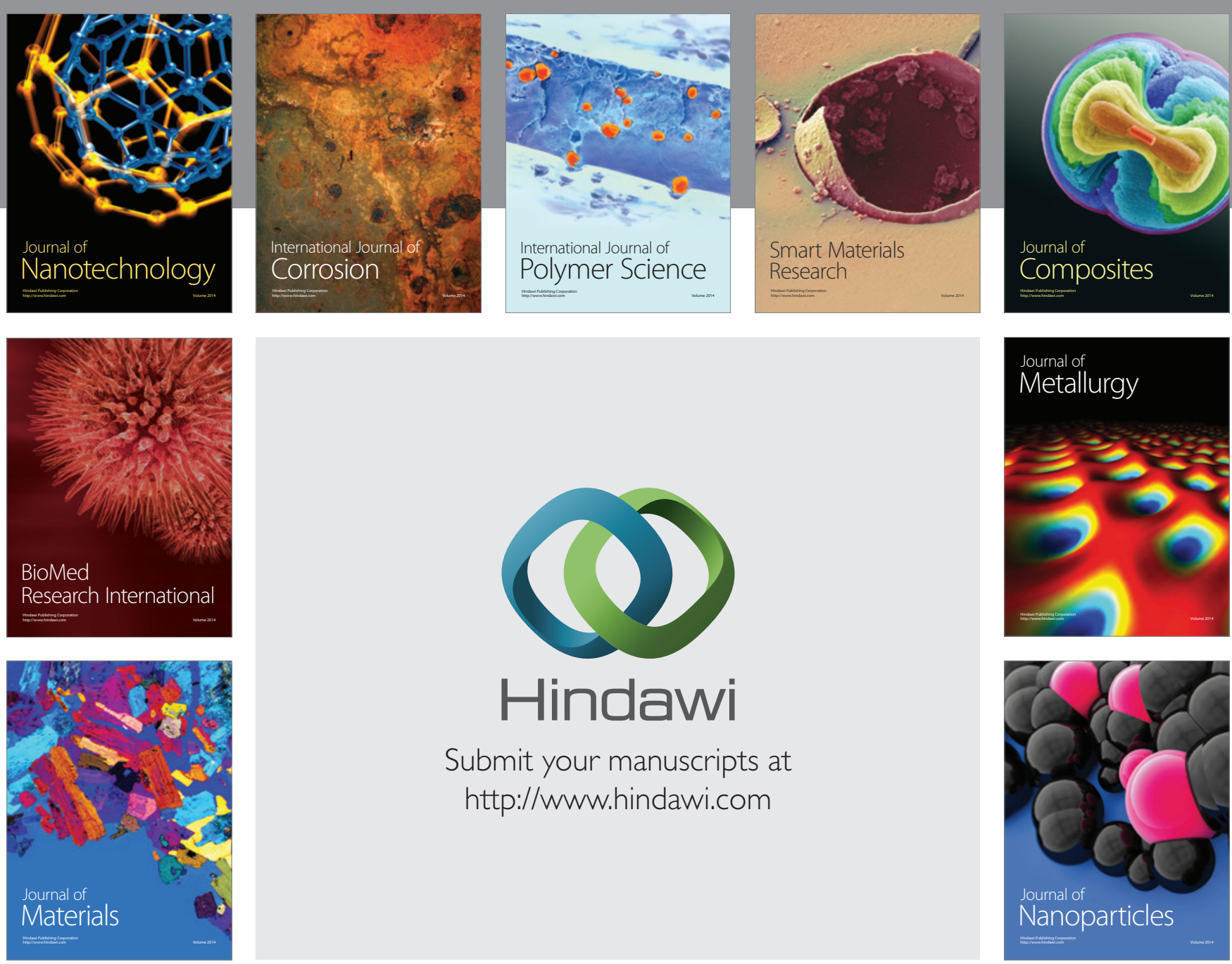

Submit your manuscripts at http://www.hindawi.com
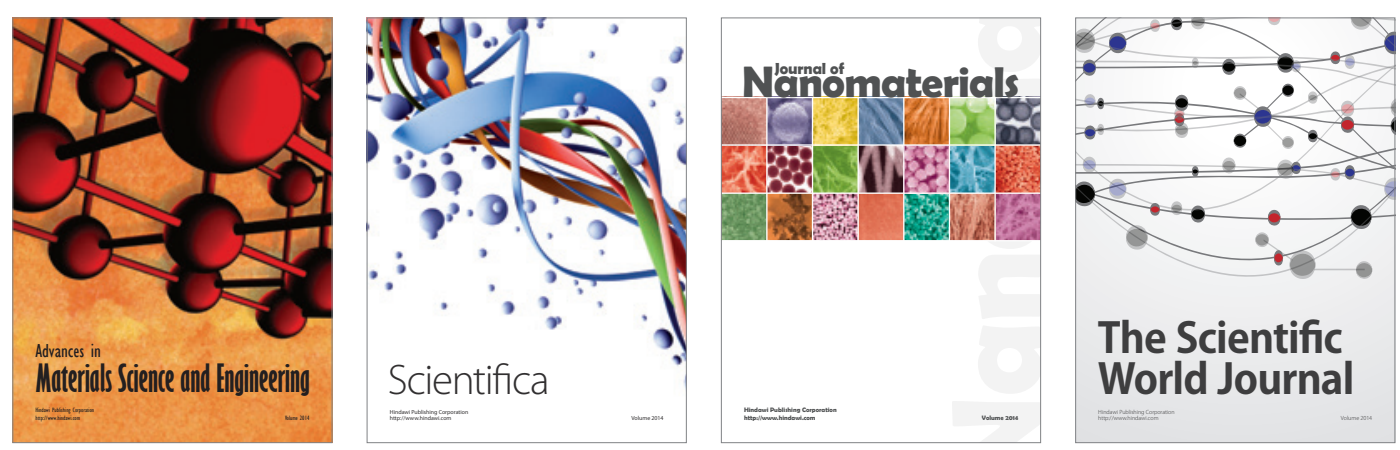

\section{The Scientific World Journal}
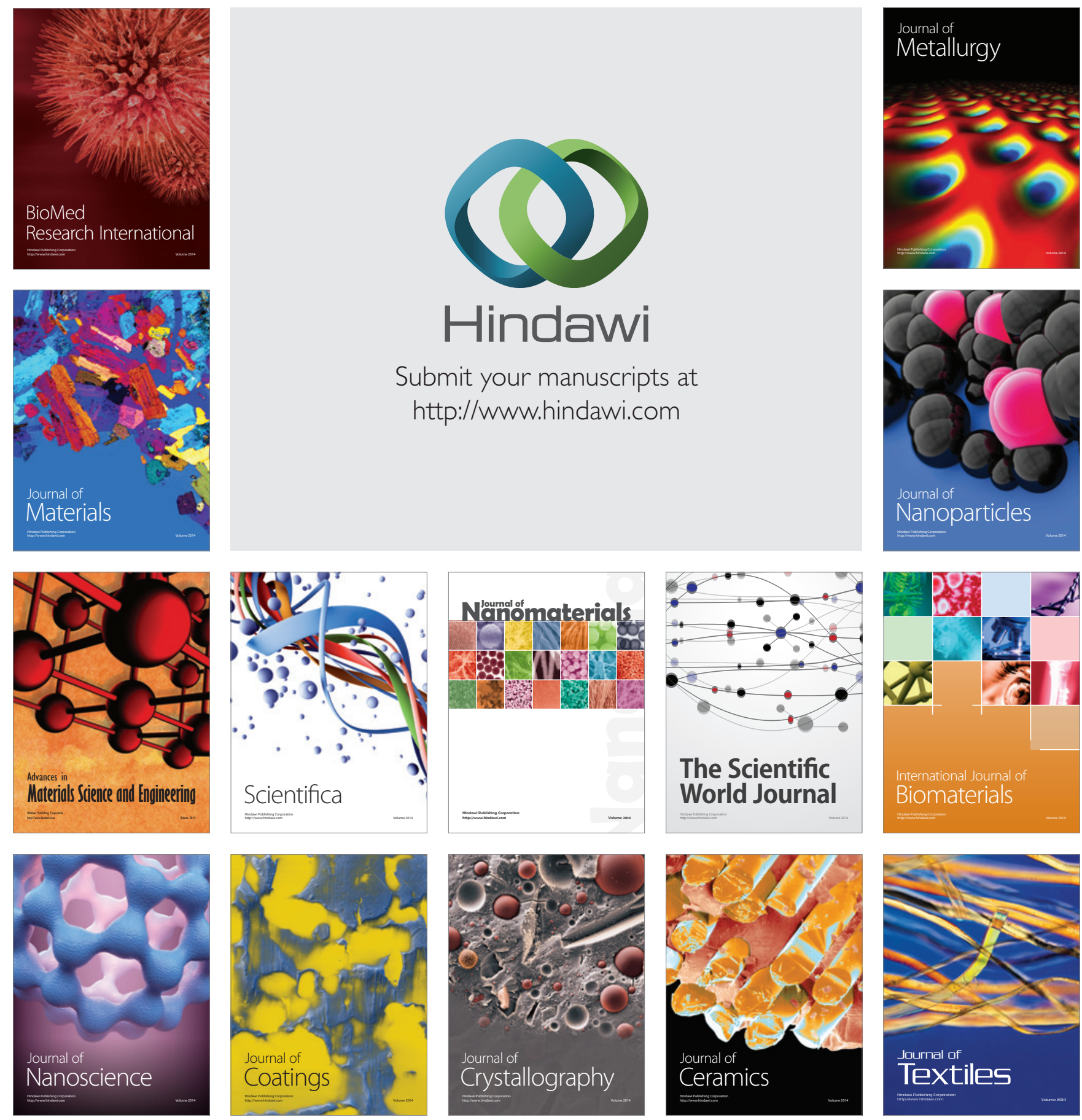